\title{
GÊNERO IMPOSTO - COAÇÃO E PUNIÇÃO HEGEMÔNICA
}

\author{
IMPOSED GENDER -HEGEMONIC COERCION AND PUNISHMENT
}

\begin{abstract}
Aldryn Cardoso ${ }^{1}$, Fátima Matos ${ }^{1}$, Rafael Fernandes de Mesquita $^{2}$ e Diego Machado ${ }^{3}$
${ }^{1}$ Instituto Superior Miguel Torga, Mestrado em Serviço Social, Portugal, email:aldryn.cardoso@live.com; e-mail:fneymatos@ismt.pt

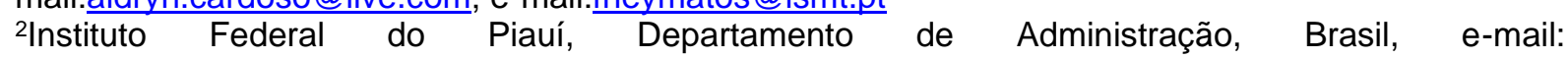
rafael.fernandes@ifpi.edu.br

3Universidade Federal do Ceará, Programa de Pós-Graduação em Administração e Controladoria, Brasil, e-mail diegomachado@ufc.br
\end{abstract}

ARTICLE INFO

Article history:

Received 2020-01-15

Accepted 2020-04-10

Available online 2020-04-10
Palavras-chave: Imposição de gênero. Sexualidade. Heteronormativismo.

Keywords: Gender Imposition. Sexuality. Heteronormativism.

RESUMO. A construção do gênero de um indivíduo é arquitetada antes mesmo do seu nascimento, por via de um sistema social consuetudinário que progride numa hegemonia amestrada em um padrão sexo-gênero-sexualidade, que torna o ser humano binário em macho e fêmea e o condiciona aos papeis sociais de ser homem ou mulher. Tal fato não contempla as plurais necessidades humanas, de gênero e sexualidade, e condiciona uma heteronormatividade hegemônica, que visa normatizar, por via da imposição, os sujeitos divergentes, os tornando alvo do sexismo e da homofobia. O objetivo deste artigo é desdobrar a cultura hegemônica da imposição de gênero e sexualidade na vida e resistência de pessoas divergentes ao heteronormativismo. Com apoio da na abordagem qualitativa, a opção metodológica recaiu sobre a História de Vida. Os relatos, embasados na literatura, apontam resultados congruentes sobre as mazelas passadas, decorrentes da imposição de gênero e sexualidade na História de Vida do sujeito. Conclui-se que, devido à natureza da divergência de gênero e sexualidade, o sujeito é mais elou menos violado em seus direitos humanos e sociais.

ABSTRACT. The construction of an individual's gender is built even before his birth, through a customary social system that progresses a hegemony mastered in a sex-gender-sexuality pattern, which makes the human being binary into male and female and conditions them to social roles of being male or female. This fact does not contemplate the plural human needs, of gender and sexuality, and conditions a hegemonic heteronormativity, which aims to standardize, through imposition, divergent subjects, making them the target of sexism and homophobia. The purpose of this article is to unfold the hegemonic culture of life's imposition of gender and sexuality and resistance of people who diverge from heteronormativism. With the support of qualitative approaches, the article is written about a Life Story. The reports, based on theories, point out congruent results about past problems, resulting from the imposition of gender and sexuality in the subject's Life History. It is concluded that, due to the nature of the divergence of gender and sexuality, the human being is more and / or less violated in his human and social rights. 


\section{Introdução}

Esta pesquisa aponta uma análise social da estrutura consuetudinária ${ }^{1}$ que determina um padrão normativo e hegemônico, que progride em condições sexistas e coercitivas a pessoas discordantes da heteronormatividade.

A compreensão hegemônica sintetiza em um sistemapadrão sexo-gênerosexualidade, como meio de ordenar a natureza do sexo, do papel de gênero e da sexualidade particular e intrínseca das pessoas. Destaca-se que os estereótipos hegemônicos, não podem ser tidos como padrão de imposição, não deve ser arquitetada uma normatização que coaja o sujeito em suas particularidades psicológicas e biológicas. De acordo com Rubin (1998, p. 106), "a sexualidade humana não é compreensível em termos puramente biológicos [pois] nunca encontramos um corpo que não seja mediado pelos significados que as culturas lhe atribuem". É necessário compreender que o ser humano é um ser plural e livre no que tange sua própria diversidade, ou seja, a forma como percebe a si mesmo e como é percebido na sociedade de pertença. Respeitar a primaziadeste direito básicoé dever do ser humano e da sociedade.

A imposição norteia-se de forma binária (masculino ou feminino) e não contempla plenamente a natureza da pluralidade humana, os sujeitos que percorrem caminhos alternativos e fluidos a esta imposição sofrem discriminações e violências concebidas pelo preconceito normatizador.

Diante desse cenário, assente na abordagem qualitativa, o objetivo é compreender como uma cultura hegemônica de imposição de gênero e sexualidade afeta a vida cotidiana e a existência da pessoa divergente ao heteronormativismo.

\section{Imposição de gênero,Sexualidade e Teoria Queer}

A sociedade ocidental atua por meio da heteronormatividade que reside na cultura e no imaginário social. Castoriadis (1982) destaca a criação da sociedade instituída como algo comum, determinando de forma absoluta o que pode ser "dizível e representável" na vida social.

A maior parte da humanidade converge a uma categorização dicotômica entre masculino e feminino, que se distingue e complementa, dentro dos papeis sociais heteronormativos, estabelecendo um conceito explicitamente determinado de que apenas a

\footnotetext{
${ }^{1}$ Apropriação da palavra dos estudos jurídicos, em particular da obra do jurista filósofo Hans Kelsen (1999), concebida por esta pesquisa como a condição ancestral da estrutura social formulada pela ordem normativa das coisas.
} 
heterossexualidade é natural ao ser humano. Tais proposições que "colocam a homossexualidade em uma posição de abjeção somente são possíveis se toda a sexualidade humana for analisada a partir da heterossexualidade como única possibilidade sexual" (MESQUITA; PERUCCHI, 2016, p. 111).

Tal imposição normativa não é percebida de forma negativa, pois progride de maneira natural na cultura e sociedade onde a pluralidade de gênero e sexualidade é marginalizada, ignorada ou punida por meio de crenças, valores e práticas heterossexistas. Para Foster (2001, p. 49), "por heteronormatividade, entende-se a urgência imperativa de ser heterossexual e defender em todos os momentos e a todo custo a primazia do heterossexual (entender o que é entendido por esse termo)".

A heteronormatividade estabelece uma simbiose entre o sexo biológico e a postura causal de género, impondo padrões identitários normativistas e machistas que progridem de forma natural na cultura e sociedade consuetudinária. Assim, problematiza e deprime a vida pessoal e social de pessoas, que mesmo sendo heterossexuais não correspondem aos critérios impostos pela heteronormatividade.

A estrutura da sociedade consuetudinária coordena a socialização nos indivíduos, antes mesmo da sua fecundação, internaliza na mente humana as condutas sexistas e padrões identitários. Desta forma, determina que apenas a heterossexualidade é natural ao ser humano e progride a ignorância, quanto as condições plurais da natureza.

A heteronormatividade flagela toda uma sociedade, pois não vitimiza apenas as pessoas que divergem das condições normativistas impostas, mas também o violador do direito humano. Desta forma o assassino, o pai que expulsa de casa, o intolerante que agride, as ofensas proferidas, os atos de discriminação - Todo este processo pune com sofrimento e/ou leis todas as partes envolvidas.

De acordo com uma vasta literatura na área (AUAD, 2004; BUTLER, 2003; JUNQUEIRA, 2007; RIBEIRO, 1996; SCOTT, 1994; WELZER-LANG, 2001), de matriz progressista, é sabido que gênero não apresenta uma única definição, fechada, calcada na imposição social ou condição biológica do sexo. Butler (2003) contribui para o debate ao observar a presunção de uma determinada política de matriz universal no que diz respeito ao universo feminino.

Embora haja uma expectativa do sistema normativo que pretende estabelecer uma continuidade, forjada como natural entre sexo-gênero-sexualidade, nem sempre tal expectativa é cumprida pelos sujeitos. Essa formatação passa por arranjos diversos, a pluralidade humana é capaz de inverter, recriar, remodelar e provocar fissuras na ordem imposta e com isso pode percorrer caminhos diversos que não conduzam necessariamente à reprodução do sistema tido como padrão. O sujeito, em sua particularidade sexual e comportamental é um ser intrínseco, com uma subjetividade muito própria e que, portanto, 
não pode ser tipificado sobre padrões preconcebidos. Segundo Goffman(1988, p. 5), “a sociedade estabelece os meios de categorizar as pessoas e o total de atributos considerados comuns e naturais para os membros de cada uma dessas categorias" e, deste modo, quem foge a tais padrões é imediatamente tipificado, estereotipado ou, nas palavras do autor, diminuído no sistema social.

É interessante perceber que neste processo consuetudinário, o sexismo progride em um conservadorismo machista nas dinâmicas sociais, que assumem uma característica homoparticipativa, condicionada, por exemplo, por meio de estruturas sociais como a escola, o exército, a igreja e as modalidades esportivas onde os homens são estimulados a unirem-se entre si, e afastarem-se das mulheres, condicionando uma relação de admiração e adoração homoafetiva.

Em uma visão ontológica desta estrutura social, a heteronormatividade, mesmo que a nível inconsciente, não permite que homens heteronormativos desenvolvam admiração/adoração por símbolos femininos, pois compreendem, resumidamente, o feminino como um ser mulher para sexualidade predatória e/ou reprodução da espécie.

Goffman(1988) nos ajuda a refletir que a identidade de gênero de um heterossexual pode ser tanto masculina como feminina quanto não binária, assim como também a de um homossexual, bissexual, intersexual, transexual, assexual ou pansexual. Scott (1994) inteirando esta linha de raciocínio, afirma que gênero, além de ser um conceito subjetivo e fluido, é também uma construção cultural da sociedade.

Quando o indivíduo não desempenha um papel de gênero conforme a expectativa da sociedade, ele acaba por sofrer diversas agressões, sejam elas físicas ou simbólicas. Welzer-Lang (2001) afirma que quando a imposição hegemônica define quem deve ser homem ou mulher, ocorre também a desigualdade hierárquica sexista, relacionada a supremacia do falo e da virilidade, onde indivíduos não submissos as imposições sofrem inúmeras formas de violências.

Contribuem para a imposição de gênero e sexualidade o conservadorismo e o sexismo que circunstanciam a violência, a discriminação, o preconceito e a homofobia, que fomentam a intolerância, a insensibilidade, e as atrocidades sofridas na pluralidade de gênero e sexualidade humana (KOEHLER, 2013).

As ciências humanas, consoante as insurgências da diversidade, buscam compreender cada vez mais a pluralidade sexual e dos papeis de gêneros na sociedade (ORNELAS et al., 2018; MESQUITA et al., 2017). A latência humana que propulsiona a identidade pessoal e aceitação social, embasada sobre contextos históricos e Direitos Humanos, aponta e revela novas possibilidades para as pessoas permitirem-se viver a identidade pessoal e progredir a percepção da diversidade humana.

A linguagem queer teve sua origem nos Estados Unidos em meados de 1980 por meio de grupos homossexuais marginalizados que buscavam o empowerment do 
termo/adjetivo "Queer", resignificando numa ação afirmativa: We're queer, we're here, get fucking used to it! (BUTLER, 1997). Anteriormente a palavra queer, de origem inglesa, era apenas um adjetivo de insulto a homossexuais, que traduzia uma criatura esquisita, estranha, ridícula (LOURO, 2001).

Atribui-se a Teresa de Lauretis a expressão "Teoria Queer", utilizada no artigo Queer Theory: Lesbian and Gay Sexualities, publicado em 1991, apesar da autora ter considerado o conceito sem significado e abdicado do mesmo (SANTOS, 2006).

No progresso da Teoria Queer, teóricos passaram a conceituar a linguagem queersob contextos sociopolíticos criticando os aspectos binários e segregatícios (homem/mulher) das categorizações de gênero, sexo e sexualidade (LOURO, 2001). Embasados nas formulações foucaultianas que abordavam o sexo de maneira histórica e por meio de estruturas de poder, emergiu a Teoria Queer:

Não se deve fazer divisão binária entre o que se diz e o que não se diz; é preciso tentar determinar as diferentes maneiras de não dizer, como são distribuídos os que podem e os que não podem falar, que tipo de discurso é autorizado ou que forma de discrição é exigida a uns e outros. Não existe um só, mas muitos silêncios e são parte integrante das estratégias que apóiam e atravessam os discursos (FOUCAULT, 1999, p. 30).

Queer significa estar acima das condições normatizadoras, negar o aceitável e o inaceitável na finalidade de legitimar sua própria identidade constituída, Louro (2001) colabora com o conceito ao afirmar:

[...] queer significa colocar-se contra a normalização - venha ela de onde vier. Seu alvo mais imediato de oposição é, certamente, a heteronormatividade compulsória da sociedade; mas não escaparia de sua crítica a normalização e a estabilidade propostas pela política de identidade do movimento homossexual dominante. Queer representa claramente a diferença que não quer ser assimilada ou tolerada e, portanto, sua forma de ação é muito mais transgressiva e perturbadora (LOURO, 2001, p. 546).

Desta forma, o desenvolvimento da Teoria Queer vem destacando-se nos estudos linguísticos, sociopolíticos e de gênero, para além disso algumas pessoas continuam a manter um posicionamento identitário queer como meio de resistência e empowerment da sua liberdade de expressão.

\section{Metodologia}

O objetivo da investigação foi compreender como a cultura hegemônica de imposição de gênero afeta a vida cotidiana e a existência de pessoas divergentes da 
heteronormatividade, portanto escolheu-se a abordagem qualitativa (MESQUITA; MATOS, 2014).

Uma das premissas da abordagem qualitativa assenta em que conhecer e compreender os indivíduos somente é possível com a descrição de como a experiência humana é vivida e definida por seus próprios atores (POLIT, BECK \&HUNGLER, 2004).

Olabuénaga (2012) considera que de todos os métodos de investigação qualitativa, provavelmente a História de Vida é o que melhor permite ao investigador compreender como os indivíduos criam o mundo social que os rodeia. Assim, a opção metodológica desta investigação recaiu sobre a História de Vida, pois buscou-se apreender e compreender um fenômeno como o mesmo é relatado e interpretado pelo próprio autor (GLAT, 1989).

A História de Vida "permite captar o que escapa às estatísticas, às regularidades objetivas dominantes e aos determinismos macrossociológicos, tornando acessível o particular, o marginal, as rupturas, os interstícios e os equívocos, elementos fundamentais da realidade social [...]" (DIGNEFFE \&BECKERS, 1997, p. 209). Por meio de sua fala, um ator pode organizar e atribuir sentido à sua vivência e estabelecer a sua pertença a uma comunidade, a uma cultura, a grupos e/ou a classes particulares (ATKINSON, 2002). Assim, "estudar o social individualizado é estudar a realidade social" (LAHIRE, 2005, p. 14).

A pessoa colaboradora nesta investigação foi apresentada por uma amizade de alguns anos que tomou conhecimento de nossa busca por um sujeito brasileiro, divergente da heteronormatividade e detentor de representatividade social em seu meio. Após a apresentação de ambas as partes, houve amplo interesse e prontidão para a participação da investigação.

Por ser militante nas causas de Direitos Humanos e LGBTs e pessoa pública, o participante optou pela divulgação de sua identificação e dados. Assinou o Termo de Consentimento Livre e Esclarecido (TCLE) e o armazenamento dos áudios ocorreu com anuência do mesmo. O sujeito que colabora com sua história de vida nesta investigação chama-se Helloy Scárdua, tem 28 anos, é brasileiro, natural do estado do Espírito Santo (ES), cursa ensino técnico em enfermagem, trabalha no Grupo Orgulho Liberdade e Dignidade (GOLD) atuando como educador social, onde também assume a função de agente na prevenção de Infecções Sexualmente Transmissíveis / Síndrome da Imunodeficiência Adquirida (IST/AIDS). Para além disso, compõe o Conselho Municipal de Direitos Humanos e o Conselho Estadual LGBT em Vitória-ES. Define-se como um indivíduo homossexual do sexo masculino e de gênero fluido, onde não assume em exclusividade nenhum dos papeis sociais binários de gênero (homem/mulher), definindo-se desta maneira como um sujeito queer.

Trata-se de um caso de representatividade de pessoas divergentes da heteronormatividade, apontando valores, definições, atitudes e necessidades dos grupos que divergem das condições de gênero impostas pela hegemonia. 
O instrumento de coleta foi a entrevista aberta; dadas às circunstâncias da pesquisa ser desenvolvida em Portugal e Brasil, foi utilizada a rede de WhatsApp, onde o participante falou sobre suas experiências na vida em quatro momentos de diálogos, todos no mês de agosto de 2018, nos dias 13, 15, 19 e 26,com duração total de 1h26min de áudio.

Após a transcrição, o tratamento dos dados foi feito por análise temática, sendo construídas categorias analíticas a partir do discurso do participante. Embora em História de Vida, o relato não siga um roteiro pré-estabelecido, pois os assuntos fluem de acordo com a experiência vivida pelo indivíduo, a fim de objetivar a investigação, foram feitas análises por categorias apriorísticas, dispostas em família, religião e trabalho. Vale mencionar que as categorias são permeadas entre si, pois compreendem a vida de uma pessoa, e embora o texto ocorra em sequência, a compreensão e o entendimento devem buscar uma visão holística.

É importante salientar que em uma História de Vida não é confirmada a autenticidade dos fatos narrados, pois mais importante é o ponto de vista de quem está narrando (BERTEAUX, 2005).

\section{História de vida de Helloy Scárdua}

Eloy Henrique Scárdua Júnior nasceu na cidade de Serra no Estado do Espírito, Brasil, no dia 02 de julho de 1990. Fruto de um triângulo amoroso, ao qual sua mãe, dividida entre os sentimentos pelo esposo Eloy Henrique Scardua e o amante Luiz, engravidou. Como epílogo Luiz foi o responsável por sua produção biológica e Eloy Henrique Scardua o pai de registro. Com a morte trágica de sua mãe, Eloy Henrique Scardua Júnior, aos 6 meses de vida, foi entregue aos cuidados de sua avó materna, Erly.

Aos 6 anos de idade Eloy já desenvolve relativa responsabilidade para ministrar alguns cuidados a mãe/avó portadora de AIDS. Nos anos 1990, na conjuntura socioespacial de Eloy, predominava o preconceito e a ignorância da população quanto às pessoas soropositivas, desta forma, desde cedo Eloy passa a conviver com a segregação e a discriminação social que percorrerá toda a sua luta e resistência.

Na categoria Família, buscou-se conhecer melhor a concepção pessoal e os vínculos emocionais e sociais que surgiram dos relatos de Helloy Scárdua. Ao compreender-se como um sujeito queer/não binário, Helloy relata a forma como se sente visto pela sociedade:

Eu me sinto um Alien - Realmente eu sou um Alien.

As pessoas acham que sou um transexual que não chegou num processo. Eles acham que eu estou sempre em transição, sempre acham que eu estou caminhando para ser uma mulher trans e não que o meu processo já está completo; que eu sou uma pessoa que aceitou que pode usar roupas 
que são distintas para os dois gêneros: usar coisas femininas quanto masculinas (SCÁRDUA, 2018).

A fala de Helloy vai ao encontro de Goffman (1988), quando aponta que a discrepância entre a identidade social real e a virtual leva a reclassificar um indivíduo antes situado numa categoria socialmente prevista, colocando-o numa categoria diferente, mas igualmente prevista. Ao sentir-se um Alien, sente-se como um ser diferente, esquisito, estranho (LOURO, 2001).

Como nasci com pênis ganhei uma "caixinha azul", e nessa "caixinha azul" tínhamos tudo o que uma pessoa com um pênis deve ter, tanto de forma moral, social ou vestuário. Também comportamental/sentimental. Abrange tudo essa questão de gênero! Como eu nasci com um pênis eu não podia chorar, eu tinha que gostar de carrinhos, a cor azul era a minha cor, eu tinha que gostar sempre do azul... Para mim a violência era sempre estimulada, eu tinha que bater, brincar de lutinha. Só que eu vi as coisas da outra caixinha, da caixinha que tinha vagina, e ai, eu gostava de bonecas, eu gostava da variedade de roupas, maquiagem, pintar as unhas, poder chorar, andar de mãos dadas com a melhor amiga, mostrar sentimentos e vulnerabilidade. $\mathrm{E}$ ai, eu vi que tinha uma outra caixinha rosa que também era legal. Por que eu tenho que ficar só dentro da caixinha azul? ... Eu me vejo como uma pessoa que tem um pouco dos dois gêneros (SCÁRDUA, 2018).

Fica perceptível o privilégio da heterossexualidade (PELÚCIO, 2009), com a imposição clara de género e seus efeitos coercitivos, como mostram os achados de (NAVASCONI; MOSCHETA, 2017). As brincadeiras próprias de meninos e de meninas objetivam a construção da heterossexualidade (RIBEIRO, 1996).

O sistema de imposição de gênero é consuetudinário, ou seja, ordinário nos costumes de uma sociedade já formulada, pois trata-se de um conservadorismo ideológico e sexista que condiciona os indivíduos machos e fêmeas aos papeis sociais de homens e mulheres, institucionalizando em uma sociedade binária e heterossexista que discrimina pessoas divergentes (CORNWALL et al., 2008).

É preciso salientar que pessoa divergente da heteronormatividade é todo sujeito que independente de seu gênero e sexualidade, contesta ou não pactua com o pensamento normativo de sexo-gênero-sexualidade, não condicionando o conservadorismo e sexismo nas coisas e pessoas. Percebe-se, então, que as concepções heteronormativas pungem não apenas a homossexuais, mas todos os indivíduos que progridem ou defendem uma postura ou pessoa que seja divergente às normas impostas.

A imposição hegemônica não permite que crianças ajam assexuadamente, desde cedo já devem demonstrar as condições de virilidade ou feminilidade, assim como, também corresponder aos papeis sociais de gênero predefinido em conformidade binária do sexo, conforme mostra Ribeiro (1996), quando aponta que os modelos de masculino e feminino 
fornecem os esboços para o esquema sexual, que possibilita à criança agir e operar sobre o meio que denota a sua organização interna.

Quanto a minha avó Erly, que me criou desde a infância, também me via como uma pessoa diferente, e ela sabia pela experiência de ser prostituta o que gays e travestis sofriam na rua, e aí, na fala dela, para me proteger, ela me violentava, me batia tentando a todo custo me corrigir que eu virasse homem [...] Eram muitas surras, muitas surras mesmo; e eu não conseguia ser diferente, né! Também ser diferente do que? Nem sabia o que ser gay era (SCÁRDUA, 2018).

Aponto na citação de Helloy a relembrança da fala de Erly: "Para me proteger", seguindo o raciocínio de por ter vivido em meio a prostituição temia as atrocidades hediondas ocorridas a gays e homossexuais no Brasil, país que mais mata por homofobia (MOTT; MICHELS; PAULINHO, 2018).

As formas ou meios de impor um sistema de sexo-gênero-sexualidade domina diversos núcleos sociais e culturais, contudo a família é a primeira instituição, o primeiro núcleo social que pode ajudar ou vitimar a pessoa divergente da heterossexualidade.

A religião surge sobre contexto violador, não para reforçar as violências físicas incitadas no corpo de Helloy, mas para assumir uma violência psicológica e persuasiva atuante na mente, com a finalidade de fazer o próprio indivíduo obrigar-se a imposição de gênero e heteronormatividade.

Ela [Erly] se tornou evangélica quando saiu da prostituição e ela achava que eu ser afeminado era algum tipo de possessão demoníaca, maldição hereditária... Espíritos... E todas essas coisas... Que eu não poderia ser uma coisa natural. E aí ela me obrigava a ir para igreja, me obrigava ir em escola bíblica dominical (SCÁRDUA, 2018).

Atuando de forma a legitimar o sexismo e a heteronormatividade a religião atribui ao sujeito divergente o sentimento e concepção de ser um indivíduo impuro e não natural à criação humana.

Dessa forma, a homossexualidade passa a ser vista como pecado e a pessoa homossexual como possuída ou influenciada pelo demônio, logo, a salvação estaria na conversão à religião, concebida como libertadora (MESQUITA; PERUCCHI, 2016).

O pecado também é um enunciado com efeitos de poder relevantes na esfera religiosa, envolvendo diversos trechos da Bíblia para reforçar a ideia de homossexualidade como pecado, perversão, abominação, prática antinatural, aberração, dentre outros...

A religião traz muito sofrimento quanto a isso, muito mesmo. Quando ia aos cultos, orações e retiros que minha avó me obrigava, eu sempre voltava com a sensação de ser alguém muito errado ou desconfigurado, que eu não era digna do amor de Deus e nem de orar ou prestar culto a 
Deus. $E$ isso me é negado até hoje, por ser divergente... (SCÁRDUA, 2018).

Embora a religião possa promover certa socialização humana a mesma também opera sob as normatividades da ordem consuetudinária, e revela-se como engrenagem criacionista de um fundamentalismo sociopolítico. Assim, há o acolhimento dos/as homossexuais pela igreja, desde que eles/as reconheçam que precisam mudar seu comportamento (MESQUITA; PERUCCHI, 2016).

Despreparado para a autonomia de sua vida e com a morte de sua mãe/avó Erly teve de ressignificar seu meio de vida.

Pronto, eu era uma pessoa obsoleta, inútil, pois até então só vivia para cuidar de outrem e agora não existia mais outrem (SCÁRDUA, 2018).

Eu não sabia o que fazer... Passaram-se quinze dias e eu comecei a trabalhar no Bob`s e depois na casa dos outros com faxina... Eu só precisava manter minha independência, não morar com ninguém e pagar minhas contas... Só que a vulnerabilidade social estava muita, sabe? Eu não consegui estudar e não conseguia progredir... Não tinha terminado o Ensino Médio! Daí fui à prefeitura, conversei com a assistente social, ela falou: "Olha, você é uma pessoa em vulnerabilidade social, você tem que estudar". Daí recebi o benefício do aluguel social, e em seis meses, por meio do EJA (Educação de Jovens e Adultos), terminei o Ensino Médio. Depois, em um ano e meio terminei o Técnico em Administração, enquanto trabalhava em uma sorveteria no bairro mesmo. Eu ia na parte da manhã trabalhar na sorveteria, saía às $18 \mathrm{~h}$ e pegava na escola às 18:30h (SCÁRDUA, 2018).

Siqueira e Andrade (2012) apontam que uma das tipologias de violência que permeia as relações de trabalho, nos mais diversos tipos de empresas, é a violência contra a homossexualidade, seja por atos explícitos de homofobia, por verbalizações com duplo sentido, piadas depreciativas ou restrições a promoções, por exemplo.

[...] é mais difícil conseguir empregos regulares/formais. Porque as pessoas julgam dentro dos padrões escolhendo uma aparência que não causem problemas para empresa. E também a força da religião, por exemplo, a maior parte das empresas perto daqui de casa são de cunho evangélico, um viés evangélico, geralmente coordenadores, diretores colocam suas religiões dentro da empresa e aí complica ainda mais a vidinha da gente... (SCÁRDUA, 2018).

Os estabelecimentos empregatícios não são assépticos quanto à heteronormatividade, embora Helloy diga não demandar consternação com certas discriminações ocorridas em seus ambientes de trabalho, relata alguns fatos em sua reminiscência:

Eu, por exemplo, não podia usar maquiagem, e as meninas podiam, eu tinha o cabelo grande e as meninas também, mas eu sofria pressão para cortar o cabelo, mas eu: "Ora! Não está dentro da touca, ninguém vai ver 
um cabelo debaixo da touca e de um boné, né!". Até no começo me foi indagado se eu estaria disposto a cortar meu cabelo. Eu falei que sim, mas daí eu fui enrolando, enrolando, enrolando... Mas foi ruim... (SCÁRDUA, 2018).

No relato acima é visível que a questão não está na condição do cabelo comprido ou curto, quando às questões da higiene e aparência estão solucionadas no uso da touca e boné. Desvenda-se aqui, uma das formas decoação e hierarquização da imposição de gênero, a heteronormatividade.

Outro relato surge quando trabalhava na sorveteria de seu bairro, este, porém não se trata apenas de uma forma de preconceito, mas violação pública da dignidade e competência humana, assumindo claramente as condições legais da discriminação:

[...] que me deixou muito assim... constrangida, foi um grupo de evangélicos não querem ser atendidos por mim na sorveteria, e esperarem até um outro atendente desocupar para atendê-los. Então isso me gerou um desconforto porque eles estavam ali para serem atendidos e eu tive de chamar os próximos, e como era um grupo de seis pessoas, imagina o volume de seis pessoas na fila, tendo que sair a sétima pessoa da fila para vim ser atendida na frente porque eles estavam aguardando outra pessoa para atendê-los. Foi uma coisa que me deixou um tanto constrangido no momento, mas a vida segue... (SCÁRDUA, 2018).

O preconceito para com a não heterossexualidade age desqualificando o profissional diante de seus colegas, chefes e subordinados, ocorrendo o preterimento profissional, a exclusão e a marginalização do homossexual no ambiente de trabalho (BICALHO et al., 2011).

\section{Conclusões}

É verossímil saber que a todo instante pessoas divergentes da heteronormatividade têm suas vidas cada vez mais violadas ou exterminadas. As violências vividas por Helloy Scárdua não se findam na conclusão deste artigo. $O$ cotidiano da sociedade normativista e conservadora trabalha a cada milionésimo de segundo com imensuráveis formas de impor o gênero e sexualidade.

A imposição de gênero possui desfechos distintos, por vezes a homofobia, que transita entre formas letaise deteriorantes da vida e dignidade dos sujeitos. Onde a desgraça não está restritaà natureza da morte. A desgraça está no fato de ser um sujeito desprezado e violentado no decorrer da vida,ante a morte natural.

A imposição de gênero não contradiz nem abala a hegemonia e o sistema sociopolítico, pois a mesma é naturalizada na sociedade pelas normas conservadoras, sexistas e fundamentalistas. Assim, a pluralidade de gênero e sexualidade não usufruem de 
igualdade de direitos, não existem direitos sociais se parte da sociedade é submetida a condições excludentes pela hegemonia.

Os direitos sociais devem abarcar toda a sociedade. Entretanto, reconhecer as especificidades da diversidade humana torna-se fator fundamental. É preciso medidas congruentes que assegurem a equidade dos direitos sociais e resguarde a diversidade humana. Isto implica a criação de projetos, programas, leis e sistemas que zelem pelos sujeitos em suas condições plurais.

As especificidades dos grupos sociais, decorrentes de condições históricas e culturais ou das diferenças inscritas nos corpos e socialmente significadas, requerem condições especiais para que se alcance a igualdade entre os diferentes grupos. Os direitos elaborados sob a orientação deste princípio filosófico-político são chamados direitos equivalentes. São direitos diferenciados, mas que não visam instituir privilégios, e sim, promover a igualdade de condições de vida entre indivíduos diferentes (P. SCOTT, LEWIS, \& de QUADROS, 2009).

Para superar as violações e sofrimentos vivenciados na sociedade por conta do sistema opressor sexo-gênero-sexualidade, é necessária atuação a nível político, sendo a questão tratada em âmbito escolar, a fim de promover, no cotidiano das famílias e da sociedade a valorização da vida e suas condições plurais. Proporcionar o entendimento da diversidade humana, na finalidade da promoção dos valores humanos sob as identidades e sexualidades pessoais. A ausência de ações preventivas e protetivas na gestão política e o viés do conservadorismo religioso, naturalizam o sexismo e progridem a imposição de gênero que coage e flagela a liberdade de sujeitos diversos.

Uma mudança nos parâmetros da educação escolar é um início, um passo, uma forma de atribuir abertura de compreensão ao diverso, de trabalhar a aceitabilidade e combater as violências ocasionadas pela imposição de gênero e sexualidade. Ainda assim tal medida não é regulada pelo Congresso brasileiro.

Não se trata de uma tarefa fácil, visto a influência estrutural consuetudinária na sociedade. Apesar disso, os valores morais, assim como as regras sociais, mudam de acordo com os interesses, com o tempo, com o grau de conhecimento e liberdade de questionamento da sociedade.

Foram múltiplas as formas de agressões e coerções sofridas no relato da vida de Helloy Scárdua, a investigação revela da infância à adolescência: Opressão psicológica, violência física, intimidação sexual e coibição em cárcere privado, todas estas violações impostas por seus familiares devido a sua natureza discordante de gênero e sexualidade. Socialmente, com a morte de sua mãe biológica, pode-se verificar a segregação social dada a convivência com pessoa portadora de Síndrome da Imunodeficiência Adquirida - AIDS (ou SIDA), ainda, grande parte do abandono familiar devido sua gestação fora do casamento e sua discordância às expectativas heteronormativas. 
Por meio de mecanismos internalizados na sociedade consuetudinária o conservadorismo e o sexismo criam ferramentas físicas e psicológicas de coação, agressão e discriminação para impor uma identidade de gênero e adestrar uma sexualidade, condicionando o heteronormativismo que afeta o desenvolvimento da vida de pessoas não heteronormativas, reproduzindo a homofobia que devasta incalculavelmente toda a sociedade, seja por meio das penalizações legais aos agressores, seja por meio dos sofrimentos pungidos a pessoa diversa.

\section{Referências}

ATKINSON, R. The Life Story Interview. Thousand Oaks: Sage, 2002.

AUAD, D. Relações de Gênero nas práticas escolares: da escola mista ao ideal de coeducação. Faculdade de Educação da Universidade de São Paulo. Tese (Doutorado em Educação - área de Sociologia da Educação), 2004.

BERTEAUX, D. Los relatos de vida. Barcelona: Bellaterra, 2005.

BICALHO, R. A. et al. Violência simbólica e homossexualidade: um estudo nas principais cidades brasileiras. Jornal do Extremo Oriente de Psicologia e Negócios, v. 5, n. 1, p. 122, 2011.

BUTLER, J. Excitable speech: a politics of the performative. New York: Routledge, 1997.

BUTLER, J. Problemas de gênero - Feminismo e subversão da identidade. $1^{\mathrm{a}}$ ed. Rio de Janeiro: Civilização Brasileira, 2003.

CARDOSO, Aldryn; MATOS, Fátima; MESQUITA, Rafael; MACHADO, Diego. Imposição de Gênero e Sexualidade: A Violência de uma Cultura Heteronormativa. In: 8 CONGRESSO IBERO-AMERICANO EM INVESTIGAÇÃO QUALITATIVA, Atas CIAIQ 2019. v. 3, Investigação Qualitativa em Ciências Sociais. Lisboa: Ludomedia, 2019. p. 439-448. Disponível em: <https://proceedings.ciaiq.org/index.php/CIAIQ2019/article/view/2286>. Acessoem: 14 jul. 2019.

CASTORIADIS, C. A Instituição Imaginária da SociedadeSão PauloPaz e Terra, , 1982.

CORNWALL, A. et al. Questões de sexualidade: ensaios transculturais. ABIA ed. Rio de Janeiro: [s.n.].

DIGNEFFE, F. \& BECKERS, M. Do individual ao social: a abordagem biográfica. Práticas e Métodos de Investigação em Ciências Sociais, p. 203-245, 1997.

FOSTER, D. W. Consideraciones sobre el estudio de la hetronormatividad en la literatura LatinoamericanaRevista do Programa de Pós-Graduação em Letras Universidade Federal de Santa Maria, 2001.

FOUCAULT, M. História da Sexualidade. 13ª ed. Rio de Janeiro: GRAAL Ltda, 1999. 
GLAT, R. Somos iguais a vocês: depoimentos de mulheres com deficiência mental. Rio de Janeiro: Agir, 1989.

GOFFMAN, E. Estigma: notas sobre a manipulação da identidade deteriorada. Antropologia Social, p. 158, 1988.

JUNQUEIRA, R. Corpo, gênero e sexualidade: Discutindo práticas educativas. Rio Grande do Sul: Ed. da FURG, 2007.

KELSEN, H. Teoria Pura do Direito ( J. B. Machado, trad.). $6^{a}$ ed. São Paulo: Martins Fontes, 1999.

KOEHLER, S. M. F. Homofobia, cultura e violências: a desinformação social. Interacções, v. 26, n. 26, p. 129-151, 2013.

LAHIRE, B. Patrimónios individuais de disposições: Para uma sociologia à escala individual.

Sociologia, Problemas e Praticas, v. 49, p. 11-42, 2005.

LOURO, G. L. Teoria queer: uma política pós-identitária para a educação. Revista Estudos Feministas, v. 9, n. 2, p. 541-553, 2001.

MESQUITA, R. F.; MATOS, F. R. N. A abordagem qualitativa nas ciências administrativas: aspectos históricos, tipologias e perspectivas futuras. Revista Brasileira de Administração Científica, v. 5, n. 1, p. 7-22, 2014.

MESQUITA, R. F., MATOS, F. R. N., SENA, A., \& LEITE, K. C. T. The multiplicity of facets of contemporary femininity in high fashion blogs. RAM. Revista de Administração Mackenzie, v. 18, n. 1, p. 96-119, 2017.

MESQUITA, D. T.; PERUCCHI, J. NÃO APENAS EM NOME DE DEUS: DISCURSOS RELIGIOSOS SOBRE HOMOSSEXUALIDADE. Psicologia e Sociedade, v. 28, n. 1, p. 105-114, 2016.

MOTT, L.; MICHELS, E.; PAULINHO. Mortes Violentas De Lgbt No Brasil Relatório 2017. Disponível em: <homofobiamata.wordpress.com>. Acesso em: 7 maio. 2018.

NAVASCONI, P. V. P.; MOSCHETA, M. DOS S. O Existente Inexistente: A Interseccionalidade de Raça, Sexualidade e Suicídio (Universsidade Estadual de Maringá, Ed.)ParanáSimpósio Internacional em Educação Sexual, , 2017. Disponível em: <http://www.sies.uem.br/trabalhos/2017/3179.pdf>

OLABUENAGA, J. I. R. Metodología de la investigación cualitativa. Sociales, Serie Ciencias, v. 15, p. 92, 2012.

ORNELAS, M. G. R., MATOS, F. R. N., MACHADO, D. D. Q., \& MESQUITA, R. F. D. Precariado e Género: a trajectória de mulheres portuguesas rumo a uma nova classe em formação. Ámbitos. Revista Internacional de Comunicación, n. 39, 2018.

PELÚCIO, L. Abjeção e desejo: uma etnografia travesti sobre o modelo preventivo de AIDS. 
Revista Estudos Feministas, v. 20, n. 1, p. 320-322, abr. 2009.

POLIT, D.F., BECK, T.C., HUNGLER, B. P. Fundamentos de pesquisa em enfermagem: métodos, avaliação e utilização. $5^{\mathrm{a}}$ ed. Porto Alegre: Artmed, 2004.

RIBEIRO, C. A Fala da Criança Sobre Sexualidade Humana: o dito, o explicito e o oculto. $1^{\text {a }}$ ed. São Paulo: Mercado de Letras, 1996.

RUBIN, G. Thinking Sex: Notes for a radical theory of the politics of sexuality. London: Routledge, 1998.

SANTOS, A. C. Estudos queer: Identidades, contextos e acção colectiva. Revista Crítica de Ciências Sociais, n. 76, 2006.

SCOTT, J. W. Prefácio a Gender and Politics of History*Cadernos Pagu - desacordos, desamores e diferenças, $1994 . \quad$ Disponível em: <https://periodicos.sbu.unicamp.br/ojs/index.php/cadpagu/article/view/1721/1705>

SCOTT, P.; LEWIS, L.; DE QUADROS, M. T. Gênero, diversidade e desigualdades na educação. Recife: Universitária UFPE, 2009.

SIQUEIRA, M. V. \& ANDRADE, A. Em busca de uma pedagogia gay no ambiente de trabalho. In Freitas, M. E. de; Dantas, M. Diversidade sexual e trabalho. 2012.

WELZER-LANG, D. A construção do masculino: dominação das mulheres e homofobia. Revista Estudos Feministas, v. 9, n. 2, p. 460-482, 2001. 